ORIGINAL RESEARCH

\title{
Assessment of Software Project Proposal using Analytical Hierarchy Process: A Framework
}

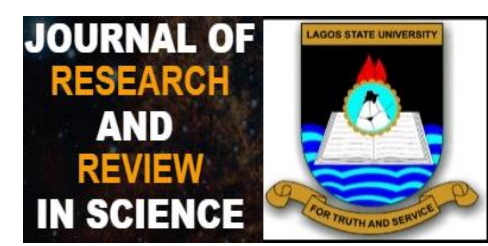

\section{Boluwaji Akinnuwesi ${ }^{1}$ and Faith-Michael Uzoka ${ }^{2}$}

${ }^{1}$ Department of Computer Science, Faculty of Science, Lagos State University, Nigeria

${ }^{2}$ Department of Mathematics and Computing, Mount Royal University, Calgary, Canada

\section{Correspondence}

Boluwaji Ade Akinnuwesi, Department of Computer Science, Faculty of Science, Lagos State University, Nigeria.

Email:Boluwaji.akinnuwesi@lasu.edu.ng

\section{Abstract:}

Introduction: Application software helps organizations to perform effectively and efficiently in the competitive environment, thus providing customers with value-added services. High significance of application software stimulates organizations to carry out thorough evaluation of software project proposals that vendors submit with the aim of selecting the best proposal. This process entails a number of assessment criteria, multiple conflicting goals, and increasingly turbulent business environment. The Analytical Hierarchy Process (AHP) provides a platform for multi-criteria assessment of quantitative and qualitative variables in the decision process.

Aim: This research focused on development of AHP based model for software project proposal assessment, which will enable decision makers in the selection of a proposal that guarantees optimal performance when implemented.

Materials and Methods: We developed an AHP-based model for selection of software projects based on pair-wise comparison data from twenty domain experts. AHP process consists of three phases: Decomposition phase for identification of decision alternatives and evaluation criteria; Measurement of Preference phase for identifying relative importance of criteria using pairwise comparison matrix; and Synthesis phase to establish percentage of relative priorities for ranking proposals and selecting the best.

Results: Sixty-four (64) variables were identified from literature and hierarchically arranged into 4 levels based on degree of preference. It was evident from the priority graph that functionality $(35.26 \%)$, quality $(22.00 \%)$ and usability (19.34\%) had the higher priority weights, while cost $(2.47 \%)$ and vendor services $(6.26 \%)$ had the least.

Conclusion: Our results point to the utility of AHP in software project proposal evaluation. AHP has been applied severally in decision modeling. An extensive literature search produced a high number of variables, which were aggregated into semantic groups. Our results indicate that functionality, quality, and usability are given high consideration in proposal evaluation, while cost and vendor services are not seen to be a critical factors.

Keywords: Analytical Hierarchy Process, Software Project, Evaluation, Selection, Organization, Multiple Decision Variables

This is an open access article under the terms of the Creative Commons Attribution License, which permits use, distribution and reproduction in any medium, provided the original work is properly cited.

(C) 2018 The Authors. Journal of Research and Reviews in Science - JRRS, A Publication of Lagos State University 


\section{INTRODUCTION}

In [1], it was reported that over $20 \%$ of the global economic activities are created through projects in order to bring strategic change and add value to organizations. Project management is a blend of scientific and professional specializations that help organizations to become efficient, effective, and competitive. Despite efforts made by researchers and professional organizations like the Project Management Institute (PMI) and International Project Management Association, some projects still fail. This causes major concern to professionals and organizations in understanding the factors that lead to project success and failure [2-5]. The authors in [6] conducted a longitudinal study involving 51 database development teams. They indicated that software projects are complex, dynamic, comprised of unstructured tasks, and dependent on diverse skill-sets of individuals. While analyzing complex adaptive systems and agile development practices, [7] stated that software development is affected by internal, external, and social factors.

It was reported in [8] that a successful software project entails the following chronological stages: selecting the best software project proposal among several proposals that vendors submit, good implementation of the approved proposal, managing business processes, and examining the practicality of the system. However, a wrong software project selection would lead to software failure and weaken the system and thus adversely impact on company performance [9-11]. In [12], the authors did a meta-analysis of 70 failed software projects with the view to understanding the causes of failures and they were able to establish wrong selection of software project proposal for implementation, as one of the causes of software failure.

Decision-making in IT project selection involve multiple, sometimes conflicting, objectives and criteria and hence called Multi Criteria Decision-Making (MCDM) [13, 14]. Often the criteria include both qualitative and quantitative factors, whereas the quantitative criteria may be measured in incomparable units (for example, the market share of a vendor and the price of a software package of that vendor). Software project evaluation and selection problems are MCDM based problems of which several methods have been proposed to help organizations make good Information System (IS) project selection decisions. The existing methodologies for IS project selection range from single-criteria cost/benefit analysis [15] to multiple criteria scoring models [9], and ranking methods [16], or subjective committee evaluation methods. Due to the characteristics of the project selection decision, analytical hierarchy process (AHP) is applied [17]. Analytic Hierarchy Process [18, 19] is one of the MCDM methods to which recently much attention is being paid.

In [11], the authors presented the variables that could be used by management of an organization to evaluate software project proposals with the view of making good and perfect selection from the list of proposals submitted by vendors for assessment. The report presented in the article is the first phase of our research that produced the required input variables to the AHP based system that we are proposing in this work. The variables listed in [11], will be fed into the AHP based model for software project proposal evaluation and selection. The second phase of our research is presented in this paper and hence we presents the conceptual framework of the AHP-based system that will help to prioritize and rank software project proposals submitted by vendors based on some decision criteria, in a step-by-step manner with the aim of selecting the best software project proposal after resolving all possible inconsistencies.

\section{MATERIAL AND METHODS}

\subsection{Review of Related Works}

Software project evaluation and selection is a complex process, which is made difficult by the multiplicity of products, variation in product performance, and uncertainties of users' needs. The selection of inappropriate packages may compromise business processes, impact negatively on the functioning of the organization, and jeopardize the very existence of the organization [11, 20]. Software products from different backgrounds are likely to exhibit different strengths and weaknesses. A weakness in one area would not necessarily eliminate a software product from consideration, as organizational requirements are not usually absolute [21]. Therefore, it is essential to utilize methodical means of evaluating and selecting appropriate software project proposal that is cost effective and suits the business process needs, structure, culture, and environment of the organization. Software evaluation and selection involves an intense activity, which could take months and a number of personnel in planning and deciding on critical concomitants that should go into decision matrix. Adoption decisions could be based on a number of factors, which could be managerial, organizational, technological, environmental, or product related [22, 23]. According to [24] software evaluation and selection is a technology adoption decision, which revolves around product and organizational characteristics. Software evaluation could be an engineering problem or customer satisfaction problem. Therefore, the emphasis is on one of two dominant perspectives, namely software engineering perspective [25] and the customer perspective [26]. It was reported in [2, 27-29] that most of the evaluation models focused on the software developer and the development process rather than extending the evaluation criteria category to customer satisfaction and perception. Customers are individuals and organizations who purchase software products and services and hence their roles in the process of software development, evaluation, adoption and utilization should not be underestimated [2, 30].

There are various procedures that can be adopted for evaluating and selecting software project proposal. A six step process (see Figure 1) of information system (IS) acquisition was presented in [31]: planning, which 
is a continuous exercise throughout the selection process; information search, which provides information used in subsequent steps; selection, which includes shortlisting of vendors and technologies; evaluation, which includes vendor, functional and technical evaluation of potential candidate in order to make a choice which eventually culminates into business and legal negotiations.

Jadhav and Sonar in [32] proposed a generic stagebased methodology for selection of any software package which consists of the following seven stages: 1) Determining the need for purchasing the system and preliminary investigation of the availability of packaged software that might be suitable, including high level investigation of software features and capabilities provided by vendor.; 2) Short listing of candidate packages.; 3) Eliminating most candidate package that do not have required feature or do not work with the existing hardware, operating system and database management software or network.; 4) Using an evaluation technique to evaluate remaining packages and obtain a score or overall ranking of them.; 5) Doing further scrutiny by obtaining trial copy of top software packages and conducting an empirical evaluation. Pilot testing of the tool in an appropriate environment.; 6) Negotiating a contract: specifying software price, number of licenses, payment schedule, functional specification, repair and maintenance responsibilities, time table for delivery, and options to terminate any agreement.; 7) Purchasing and implementing most appropriate software package. The authors found that none of the primary studies explicitly covered step 7 . However, good evaluation practice suggests that some action should be taken to ensure that the selected package performs as expected after implementation.

A methodology was proposed in [33] by using analytical framework of AHP to synthesize decision makers' tangible and intangible measures with respect to numerous competing objectives inherent in ERP system selection and other IS and facilitates the group decision-making process. They developed a procedure for selecting a suitable IS (ERP) system (See Figure 2). The proposed procedure allows a company to identify the elements of ERP system selection and formulate the fundamental-objective hierarchy and means-objective network. The pertinent attributes for evaluating a variety of ERP systems and vendors can be derived according to the structure of objectives. The procedure is as follows: 1) Form a steering committee and collect all possible information about the IT vendors and system.; 2) Identify the IT project characteristics.; 3) Construct a structure of objectives to develop the fundamentalobjective hierarchy and means-objective network.; 4) Extract the attributes for evaluating IT systems from the structure of objectives.; 5) Filter unqualified vendors by asking specific question, which are formulated as the system requirement.; 6) Evaluate the IT project using the AHP method.; 7) Discuss the results and make the final decision.

There are several methods that exist for software evaluation, depending on the perspectives, organizational needs and evaluation expertise. In [34], evaluation methods were categorized into the following: subjective evaluation methods, objective evaluation methods, cooperative evaluation methods, expert evaluation methods and experimental evaluation methods. The subjective evaluation methods are directly based on the user's subjective views of the software (e.g., questionnaires and interviews). In [27], a subjective evaluation method was adopted to evaluate the performance of distributed software system architecture. Cooperative evaluation methods involve actively involving the users of the software in the process of evaluation, while the expert evaluation methods draw upon expert knowledge to make judgments about the usability of the system for specific end users and tasks.

Listed below are some of the shortcomings deduced based on our study of previous models used for evaluating software project proposals:

a. Most of the evaluation models e.g. [2, 27-29] focused on the software developer and the development process rather than extending the evaluation criteria category to customer satisfaction and perception.

b. Most of the studies e.g. [35-37] did not suggests some actions to be taken to ensure that the

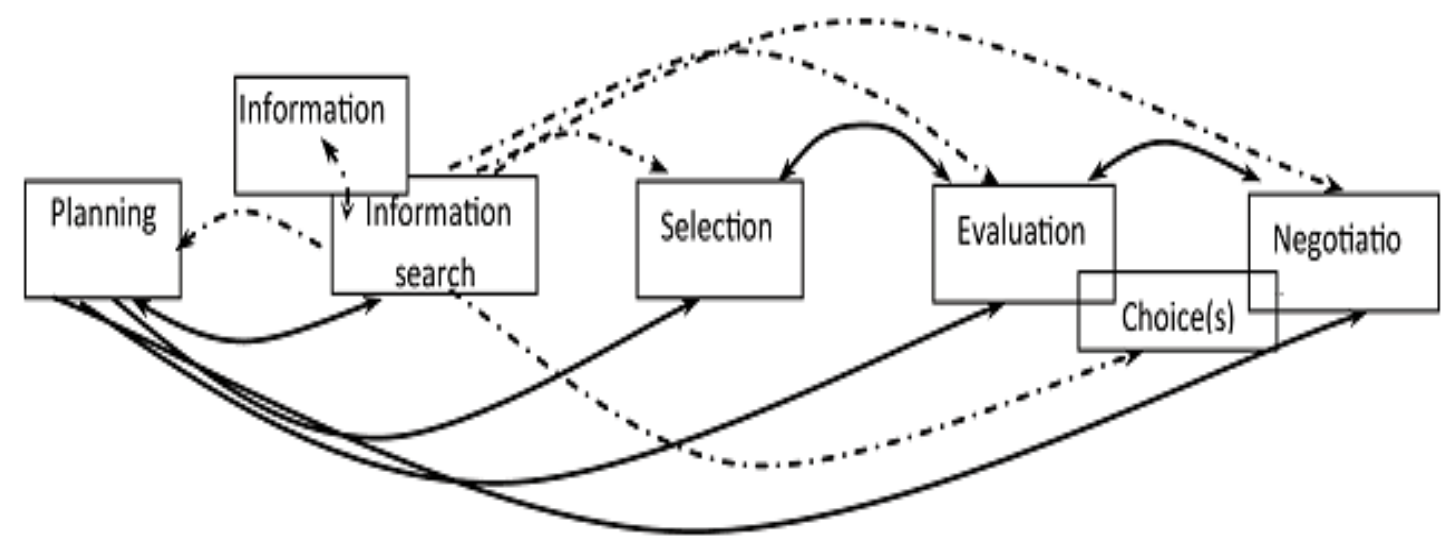

Figure 1 Model of ERP Acquisition Process [31] 


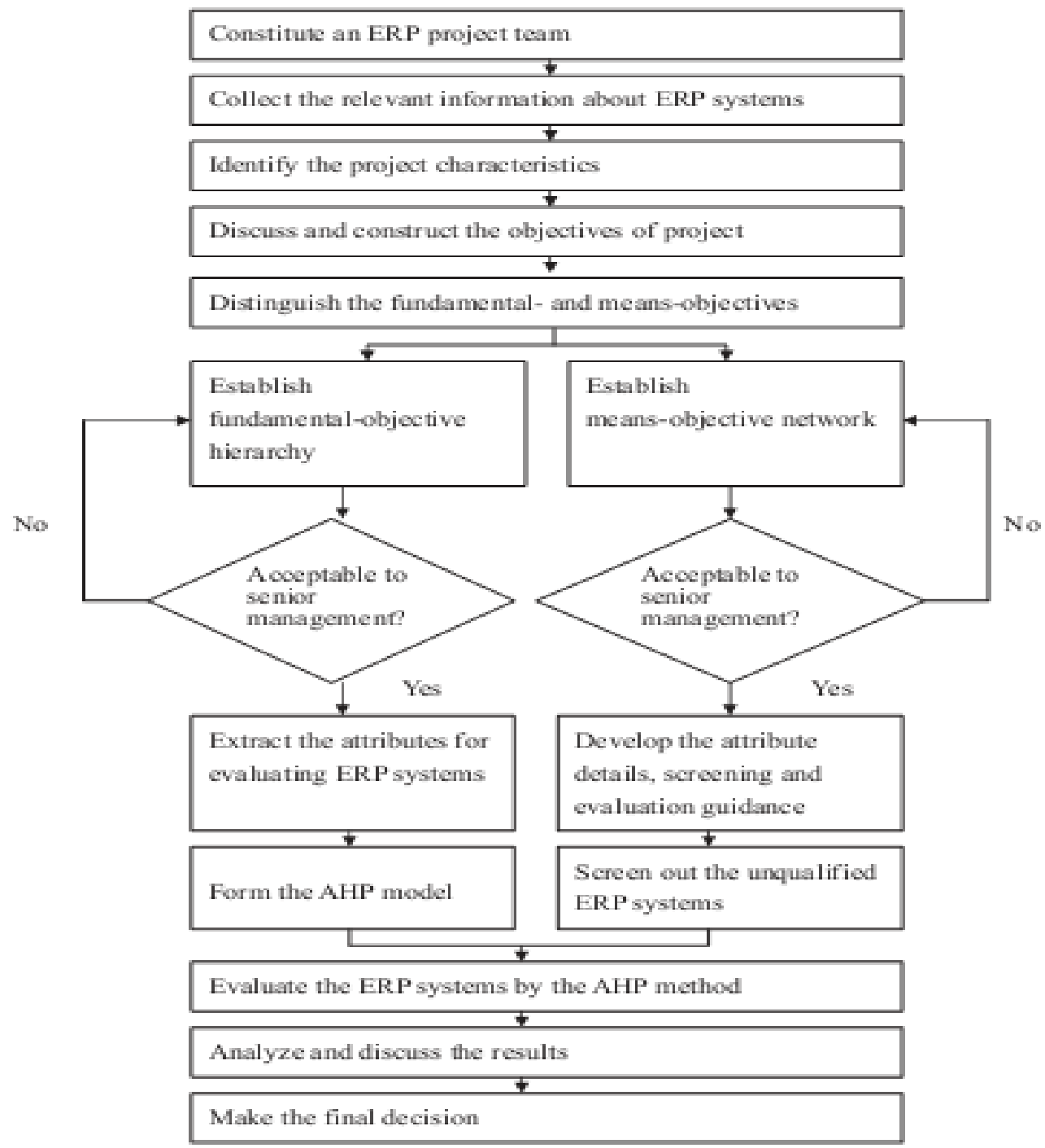

Figure 2. Comprehensive ERP System Selection Framework [33]

c. selected package performs as expected after implementation.

d. The applicability of some of the models e.g. [38-40] is most times weakened by sophisticated mathematic models vis-à-vis limited parameters for a practical software system selection decision. This occurs in most cases when the evaluation parameters are not readily quantifiable and hence not easy for managers to understand. Thus the approaches focused more on quantifiable calculations and look down on subjective evaluation which could help to have comprehensive selection framework of software system vis-à-vis the strategic considerations of the client company.

In this paper we adopted the subjective evaluation method and hence drew our evaluation criteria for decision making from the perspective of the management of the client organization. This approach will: 1) enable active involvement of the users in the client organization in the software selection and development process; 2) enable the software vendor to have intimate relationship with the entire management of the client organization and hence has less challenges during users' requirements gathering; 3) enable users to easily accept, adopt and understand the use of the software when deplored. The process of evaluating and selecting appropriate software project proposal for an organization is multi-criteria oriented and hence the use of AHP to prioritize and rank the proposals submitted for evaluation based on judgmental evaluation through peer ratings.

\subsection{Development of the Conceptual Framework of the AHP Based Model for Software Project Proposal Evaluation and Selection}

The phases of the development of the AHP framework are as follows:

\section{Phase One: Decomposition Phase:}

a. Identify all decision alternatives: For these research the decision alternatives are the software project vendors (i.e. Vendor 1, vendor 2, ... Vendor $\mathrm{n})$.

b. Identify all the criteria for evaluation: the criteria are the evaluation factors. The evaluation factors used in the proposed framework were sourced from various literatures such as $[8,10-12,19,24$, $31,33,41-52]$ 
Level 2 criteria (factors): cost, functionality, flexibility, usability, quality, vendor services.

Level 3 criteria (sub-factor): organizational cost, cost of implementation, module content, ease of customization, interoperability and completeness, system adaptability, system integration, user interest, user experience, ease of use, reliability, efficiency, vendor experience, vendor technical knowhow

Level 4 criteria (variables): service speed, defined policies, project budget, installation and implementation cost, license cost, cost of hardware, number of modules on distributed tiers, number of modules on separable server, number of modules on independently modules, number of workstation, provision of reference site, customizable fields, customizable report, customizable fields, interface type, communication standards, availability of modules to the users, completeness, interoperability, openness, parameter settings, adaptability of system, platform independence, upgradability, ease of integration with other IS, user interest with the application, willingness of user to use the system, users experience in the problem area of the system, professional qualification of the user, familiarity of the user with IT tools, length of experience user with similar applications, ease of use of graphical interface, ease of operation, stability, recovery ability, main storage constraint, service execution time, strength of communication devices, length of experience of the vendor, warranty provided by the vendor, past business experience, ease of implementation, good implementation services, technical business skills, internal technical knowledge.

\section{c. Develop the hierarchy of criteria for} prioritizations.

i. Identify the overall goal/objective of the selection

ii. Identify appropriate criteria to satisfy a goal

iii. Identify where appropriate, a sub-criteria under each criterion. This is represented in Figure 3.

\section{Phase Two: Measurement of Preference:}

Step 1: The priority model is established by identifying the relative importance of criteria through pairwise comparison (PWC) matrix. The PWC matrix is done from the top level of the hierarchy to the bottom level in order to establish the overall priority index.

Step 2: Create a matrix table for each Level based on their Upper Level: This step involves the ratio of importance of one criteria over another on a scale of 1 to 9 as it was defined by Saaty in [19] and hence produce the PWC matrix for each level.

\section{Phase Three: Synthesis Phase:}

This involves the computation of Eigen values and Eigen vector. Synthesis yields the percentage of relative priorities, which is expressed in a linear form to give the
Eigen vector. The implication of the eigenvector is that it expresses the relative importance of an attribute over another in the minds of the decision maker. The eigenvalues and eigenvector provide a means of obtaining linear relationships among the evaluation variables. A pairwise comparison matrix is a square matrix $(A v)$ that consists of scalar elements. We are interested in finding a scalar number $\lambda$ (called eigen value), such that $A v=\lambda v$, in which case, $v$ is the eigen vector. The eigen value is a scalar multiple of the eigen vector. According to Saaty in [53, 54], the principal eigenvector shows the priorities derived from pair-wise comparison matrix (PWC). Human judgment involves some level of inconsistency, which is reflected in the PWC. The principal eigenvector is necessary for representing the priorities associated with the PWC, given that inconsistency is within a threshold of 0.1 [18].

\section{Steps Involved in Obtaining the Eigenvalue and Eigenvector}

Step 1: Calculate the Eigen value for each cell. (Using major evaluation criteria PWC matrix table as an example for showing the step by step calculation in order to obtain the result). This is done by dividing the particular cell by the column total of each cell with the formula below:

$E_{i, j}=V_{i, j} / T_{j}$

Where $E=$ eigenvalues of cell $\left\{a_{i, j}\right\} ; V=$ The value of

the pairwise comparison matrix for cell $\left\{a_{i, j}\right\}$;

$T=$ The sum of the values on column $j$

Step 2: sum up the rows and column

\section{Step 3: Calculation of the Eigen vectors}

The next step is to derive the eigenvector for variable $\mathrm{k}$. This step involves the calculation of the Eigen vectors which gives the calculated weights for each major variable. The Eigenvector is calculated by dividing the row total by $n$.

$\lambda_{k}=\Sigma E_{k, j} / n ; \lambda_{k}=$ row total/n

Where:

$\lambda_{k}=$ the eigenvector corresponding to variable $\mathrm{k}$

$\left(\Sigma \lambda_{\mathrm{k}}=1\right)$

$E_{k, j}=$ the eigenvalue of cell $\left\{a_{k, j}\right\}(j=1,2, \ldots . n)$;

$\mathrm{n}=$ the number of evaluation variables

Step 4: Assess each decision alternative in terms of the lowest level sub-criteria in each criterion.

Step 5: Determine the priority order (ranking). The first priority is the best choice

Presented in Figure 3 is the conceptual framework of the proposed AHP based model for software project proposal evaluation and selection. In this research, 44 variables were used and they were loaded on 14 different factors, because of the limitation of AHP to handle too many criteria. We further group the factors into six major factors that were used as metrics for describing submitted proposals. 
Also Figure 4 presents the conceptual framework of the software architecture of the proposed AHP-based system. The User Interface is meant for easy communication with the system. Access is gained by supplying username and password, that aid access control. The IT Vendors are contracted companies interested in providing software solutions for the client organization. It is expected of the IT vendors to summit their software project proposal online. It is possible that each vendors might have possible solution to more than one IT project. The next phase is to fill in an assessment form. The various project are the alternatives considered during AHP evaluation. The organizational users tend to pin point the various IT projects the organization lacks (loops in the IT sector) and takes it out to the public. It is the duty of the organizational staff to set a standard benchmark and a threshold mark which would be assigned to the IT vendors; hence any IT vendor that does not meet the threshold mark are disqualified, thus the acceptable IT vendors will be determined by using their response to the questionnaire filled. The IT System Administrator defines the organizational variables to be used when evaluating and selecting IT project. His/Her duty is to define new set of parameters or to modify the parameters as situation may arise. For the purpose of this work 44 variables are used as parameter for evaluation. The Operational Staff provides linguistics value as response to the variables in the proposal assessment form. The Decision Maker oversees all that has been done. There should be an interaction between the operational staff and the decision maker. Though their major task is to run IT project evaluation engine and initiates the evaluation process. This involves the Inference Engine picking up values, from the knowledge base to be used for evaluation and storing immediate values in the knowledge base for use. Report Unit is responsible for presenting output to the decision maker.

\section{RESULTS AND DISCUSSION}

\subsection{Results}

In this study the decision alternatives are the software project vendors (i.e. Vendor 1 , vendor $2, \ldots$ Vendor $n$ ). The hierarchy of criteria for prioritizations is presented in Table 1 and Figure 3 below. Pairwise Comparison (PWC) matrices for Levels 2 and 3 criteria are presented in Tables 2. The scale of preference adopted for pairwise comparison of variables is in the range 1 to 9 as defined by Saaty in [19] with 1 as the least and 9 as the highest value in the scale. The pairwise comparison of variables states the relative importance of variables when compared with one another. The single-lined cells show the pair-wise comparisons for the Level 2 factors. For example, a comparison of cost (CO) and Functionality (FU) shows a value of 0.140 , but functionality against cost shows a value of 7.148. This implies that functionality is considered more important than cost by a factor of 7.148 out of 9 . The diagonal (double-lined) boxes are the level 3 pair-wise comparison matrices. The first is the PWC matrix for the cost factor, while the second diagonal box is the PWC matrix for the functionality factor. Within the functionality factor, ease of customization (CUST) is almost equally valued as interoperability and completeness (NTRP) 1.122 and 0.891 respectively.

Figures 5 presents the priority graph for Level 2 criteria. It is evident from the priority graph that functionality had the highest priority weight of $35.29 \%$, while cost and vendor services had the least priority weights of $3.47 \%$ and $6.26 \%$ respectively. The Level 2 software project evaluation criteria give an eigenvector, $\lambda 1$, while the level 3 criteria produce the eigenvector, $\lambda 2$ for each factor, and the Level 4 criteria produce the eigenvector, $\lambda 3$ for each sub factor (variable). $\lambda 1$, combines with the column vector of Level 2 factors to give the project evaluation factor index for Level 2 criteria $\left(\mathrm{PEFI}_{1}\right)$, while $\lambda 2$, combines with the column vector of the Level 3 sub factors to give the project evaluation factor index for Level 3 criteria $\left(\mathrm{PEFI}_{2}\right)$ and $\lambda 3$, combines with the column vector of the Level 4 variables to give the evaluation factor index for Level 4 criteria $\left(\mathrm{PEFI}_{3}\right)$. Thus, it is possible to evaluate the software project at various levels of factor abstractions. At a higher level, the evaluation could involve just the Level 2 criteria (cost, functionality, flexibility, usability, quality, and vendor services). Alternatively, an organization may decide to evaluate their software project in terms of the Level 3 factors (Module Content, User's Experience, Vendors Technical Know-how, Ease of Customization, Vendor Experience, System Adaptability, User Interest, Interoperability and Completeness, Reliability, Organizational Budget, Ease of Use, Integration, Cost of Implementation, System efficiency), or in terms of the 44 Level 4 sub-factors. 


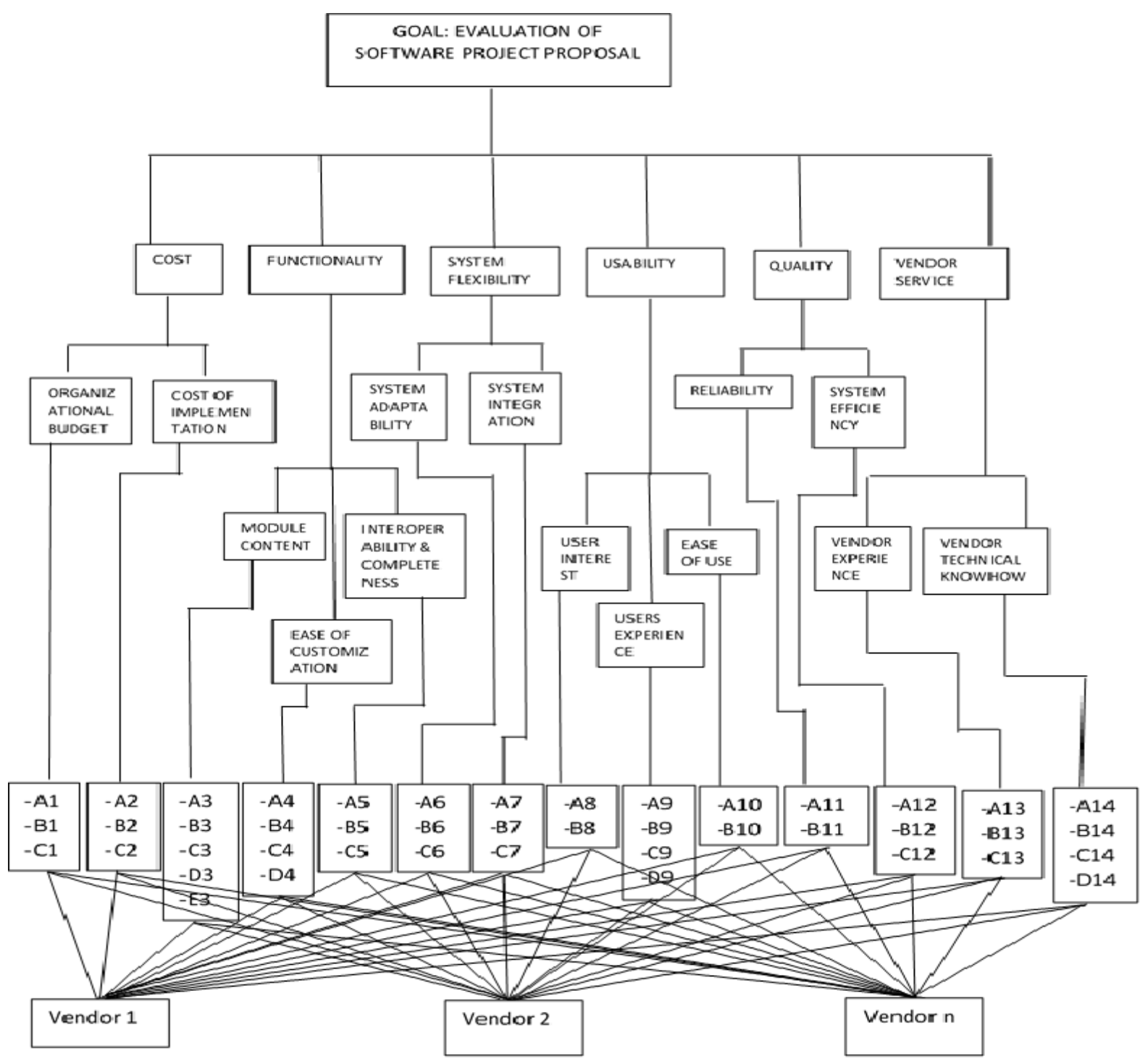

Figure 3. AHP Based Conceptual Model of Software Project Evaluation and Selection

Legend: A1: Service speed of the system; B1: Defined organization policies relating to systems and vendors; C1: Project budget; A2: Installation and implementation of the software/hardware B2: License cost; C2: Cost of hardware; A3: Number of modules on distributed tiers of the s/w B3: Number of modules on separate server; C3: Number of independently modules; D3: Number of workstation provided; E3: Provision of reference site by vendor; A4: Customizable fields in modules of the s/w; B4: Customizable report produced by the s/w; C4: User Interface type; D4: Communication standards provided by the system; A5: Availability of modules in the s/w; B5: Completeness of the software; C5: Interoperability of the system with other systems; A6: Openness of the software; B6: Parameter in the settings of the settings; C6: Adaptability in the system to the organization's environment; A7: Platform Independence; B7: upgradability of the system; C7: Ease of integration with other IS; A8: User interest in s/w; B8: Willingness of the user to use the system; A9: User experience in the problem area of the s/w system; B9: Professional qualification of the users of the system; C9: familiarity of user with the IT tools provided by the system; D9: Length of experience of user of the system; A10: Ease of use of graphical interface; B10: Ease of operation of s/w and hardware; A11: Stability of both s/w and h/w; B11: Recovery ability in case of failure; A12: Main storage constraint of the system; B12: Service execution time of the system; C12: Strength of communication devices; A13: Length of experience of vendor; B13: Warranty provided by the vendor; C13: Past business experience of vendor; A14: Ease of implementation of the system; B14: Good implementation service; C14: Technical business skills of vendor/developer; D14: Internal technical knowledge of the vendor/developer. 


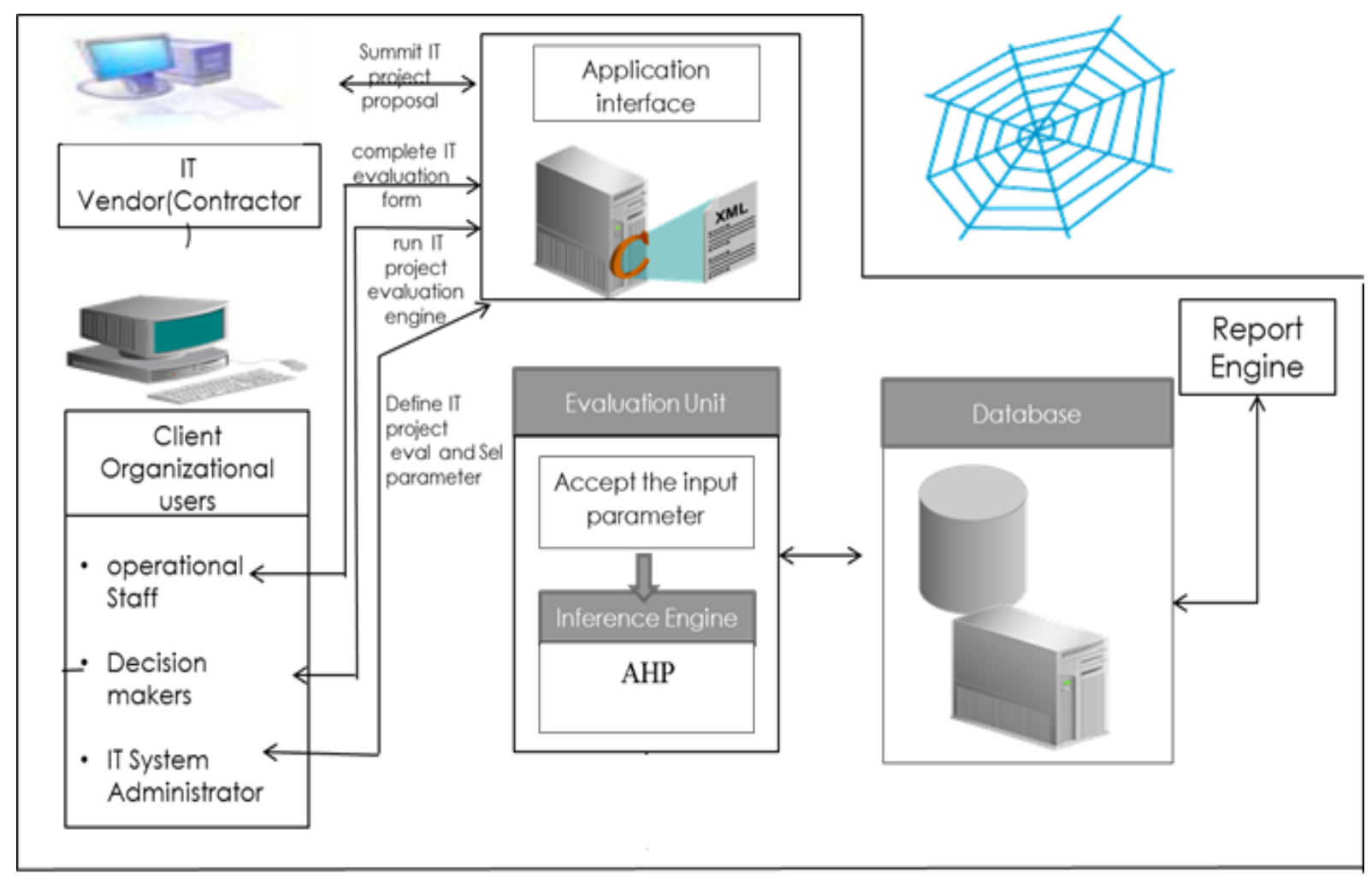

Figure 4: Conceptual Framework of the Software Architecture of the AHP-based System

\subsection{Discussion}

In this study we developed an AHP based framework for evaluating and selecting software project proposal that vendors submit to an organization. In order to achieve our aim, we adopted the results of the first phase of this research that was presented in [11] where we identified decision alternatives and variables from literatures for evaluating software project proposal and eighty three (83) evaluation variables were listed. Questionnaires were distributed to sample the opinions of software experts on the relevance of the evaluation variables and exploratory factor analysis was carried out to establish the significant variables. We established 64 significant evaluation variables after factor analysis and they were hierarchically arranged for prioritization. Hence in this study, we developed 4 hierarchical levels of AHP model [i.e. Level 0 (L0), Level 1 (L1), Level 2 (L2) \& Level 3 (L3)] which we proposed for assessment of software project proposal. Forty four (44) level 3 variables were loaded on 14 level 2 variables and 14 level 2 variables were loaded on 6 level 1 variables. The root variable (i.e. Goal ==> "software project evaluation") is evaluated based on the 6 variables in level 1 of the hierarchy (i.e. Cost, Functionality, System Flexibility, Usability, Quality, Vendor Service).
The AHP model reveals the relative importance of various factors in the software project proposal evaluation process. The results show that functionality, quality and usability are very critical in the software evaluation decision, while cost and vendor service rank low in decision process.

Data sample used for this research is limited in number and hence we could not capture wide view of people. Moreover, we do not consider implementation process for selected software project bearing in mind that adoption of wrong implementation process by the management of the client organization could be responsible for failed software solution in an organization. Therefore a future research is required on having an implementation framework that will focus on the cause and effect of the relationship that software project selection process activities have on the implementation process. We also note that the AHP model was developed using pair-wise comparison information provided by 20 domain experts in software project management. This model could be better generalized with a larger number of domain experts in various project environments, with a good diversity of constraints. 
Table 1 IT Project Evaluation Criteria Hierarchy

\begin{tabular}{|c|c|c|c|}
\hline 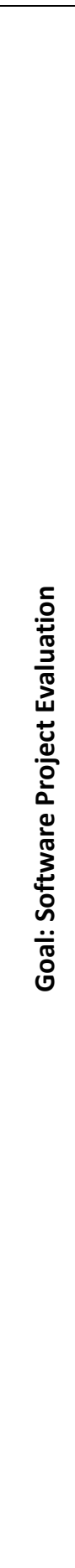 & 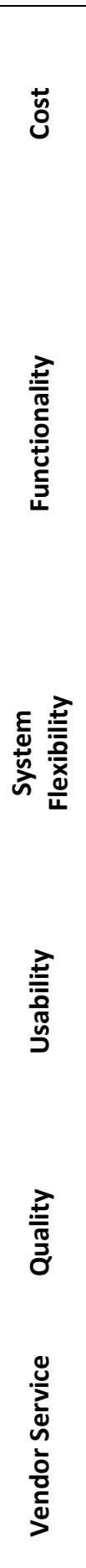 & $\begin{array}{l}\text { ORGANIZATIONAL } \\
\text { BUDGET } \\
\text { (BUDG) } \\
\text { COST OF } \\
\text { IMPLEMENTATION } \\
\text { (COST) } \\
\text { MODULE CONTENT } \\
\text { (MODL) } \\
\text { EASE OF } \\
\text { CUSTOMIZATION } \\
\text { (CUST) } \\
\text { INTEROPERABILITY \& } \\
\text { COMPLETENESS } \\
\text { (NTRP) } \\
\text { SYSTEM } \\
\text { ADAPTABILITY (ADPT) } \\
\text { SYSTEM INTEGRATION } \\
\text { (INTG) } \\
\text { USER INTEREST } \\
\text { (USINT) } \\
\text { USERS EXPERIENCE } \\
\text { (EXPR) } \\
\text { EASE OF USE (EASE) } \\
\text { RELIABILITY (RELB) } \\
\text { SYSTEM EFFICIENCY } \\
\text { (EFFCY) } \\
\text { VENDOR EXPERIENCE } \\
\text { (VDEX) } \\
\text { VENDOR TECHNICAL } \\
\text { KNOWHOW (VDTK) }\end{array}$ & $\begin{array}{l}\text { A1: Service speed of the system } \\
\text { B1: Defined organization policies relating to systems and vendors } \\
\text { C1: Project budget } \\
\text { A2: Installation and implementation of the software/hardware } \\
\text { B2: License cost } \\
\text { C2: Cost of hardware } \\
\text { A3: Number of modules on distributed tiers of the s/w } \\
\text { B3: Number of modules on separate server } \\
\text { C3: Number of independently modules } \\
\text { D3: Number of workstation provided } \\
\text { E3: Provision of reference site by vendor } \\
\text { A4: Customizable fields in modules of the s/w } \\
\text { B4: Customizable report produced by the s/w } \\
\text { C4: User Interface type } \\
\text { D4: Communication standards provided by the system } \\
\text { A5: Availability of modules in the s/w } \\
\text { B5: Completeness of the software } \\
\text { C5: Interoperability of the system with other systems } \\
\text { A6: Openness of the software } \\
\text { B6: Parameter in the settings of the settings } \\
\text { C6: Adaptability in the system to the organization's environment } \\
\text { A7: Platform Independence } \\
\text { B7: Upgradability of the system } \\
\text { C7: Ease of integration with other IS } \\
\text { A8: User interest in s/w } \\
\text { B8: Willingness of the user to use the system } \\
\text { A9: User experience in the problem area of the s/w system } \\
\text { B9: Professional qualification of the users of the system } \\
\text { C9: familiarity of user with the IT tools provided by the system } \\
\text { D9: Length of experience of user of the system } \\
\text { A10: Ease of use of graphical interface } \\
\text { B10: Ease of operation of } s / w \text { and hardware } \\
\text { A11: Stability of both s/w and h/w } \\
\text { B11: Recovery ability in case of failure } \\
\text { A12: Main storage constraint of the system } \\
\text { B12: Service execution time of the system } \\
\text { C12: Strength of communication devices } \\
\text { A13: Length of experience of vendor } \\
\text { B13: Warranty provided by the vendor } \\
\text { C13: Past business experience of vendor } \\
\text { A14: Ease of implementation of the system } \\
\text { B14: Good implementation service } \\
\text { C14: Technical business skills of vendor/developer } \\
\text { D14: Internal technical knowledge of the vendor/developer. }\end{array}$ \\
\hline
\end{tabular}


Table 2 Levels 2 and 3 PWC Matrix

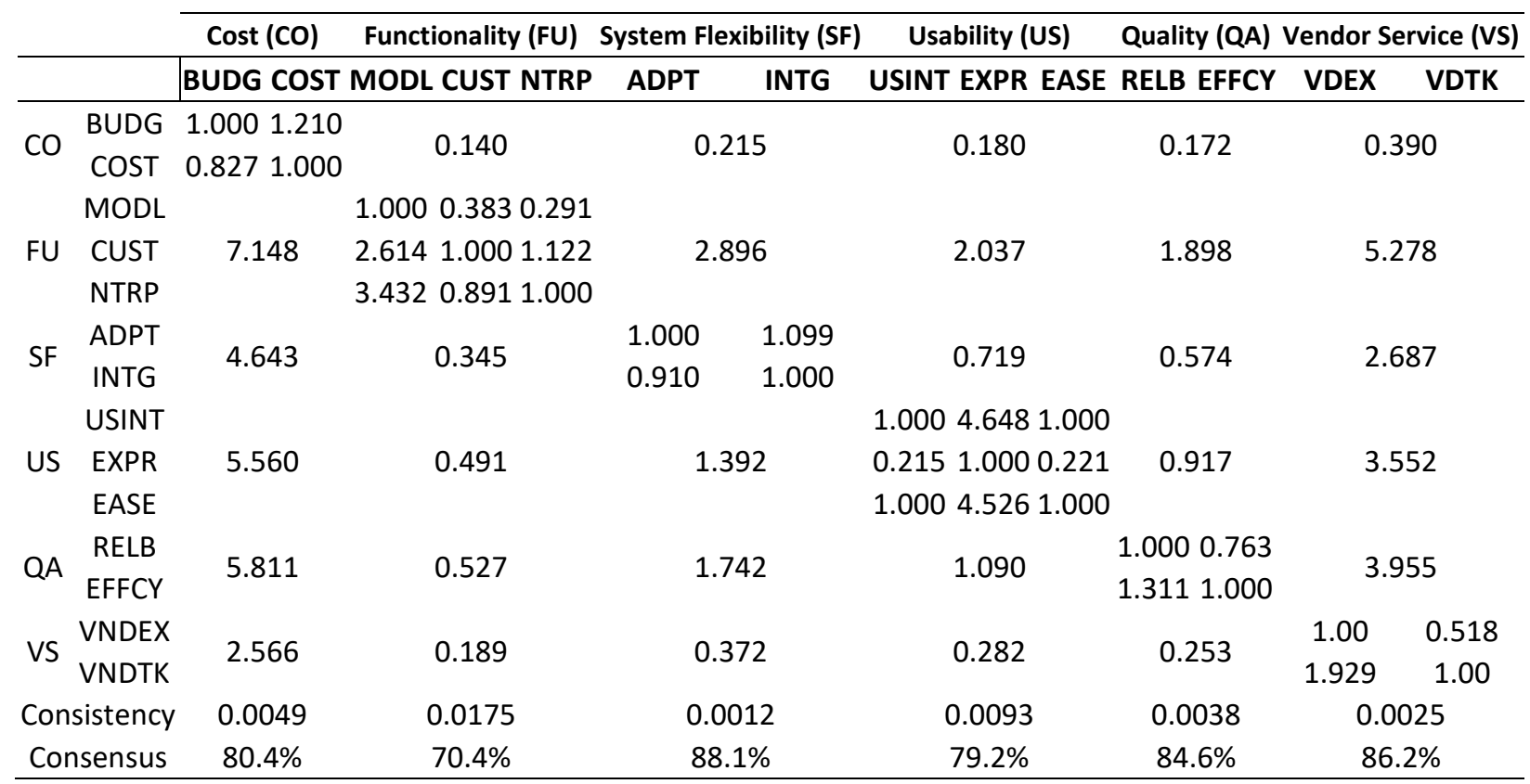

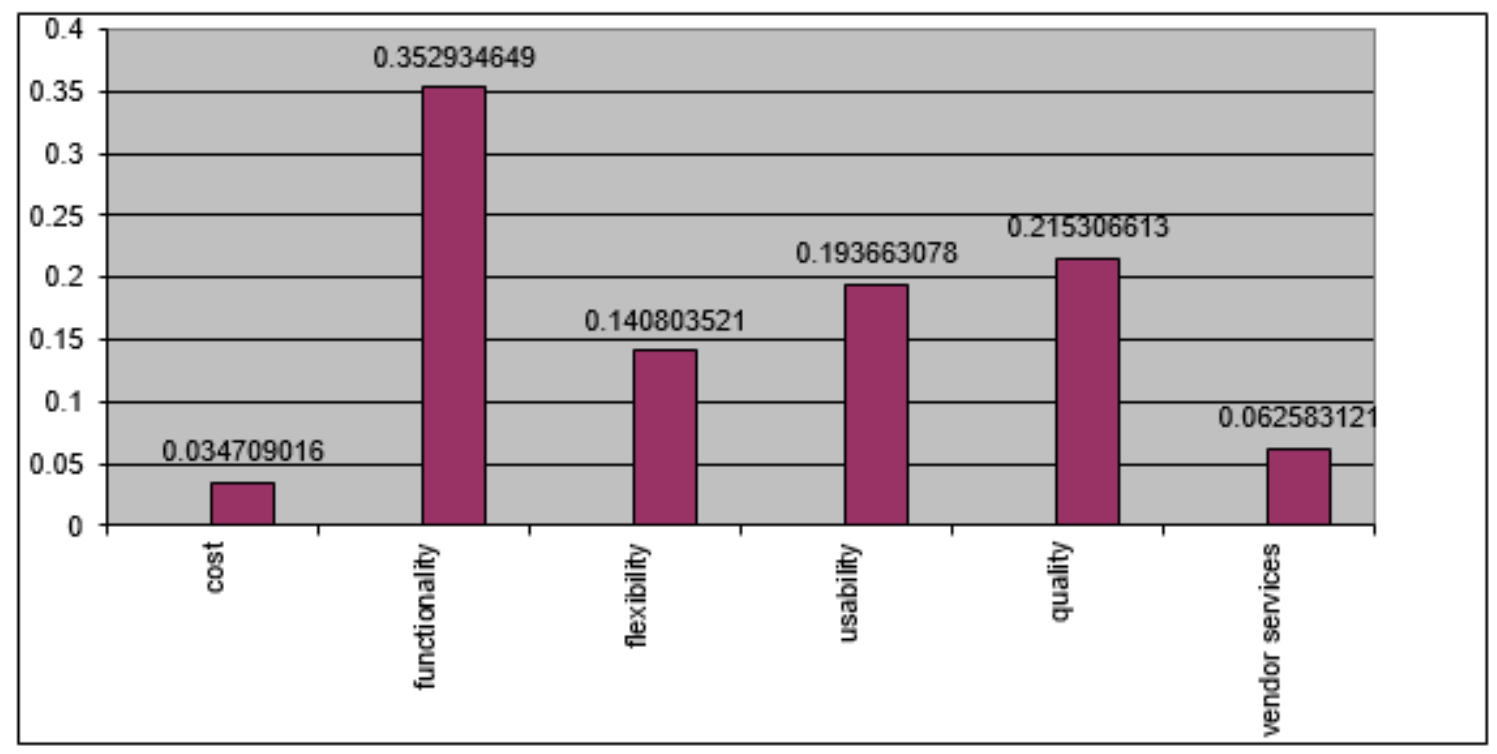

Figure 5 Level 2 Criteria Priority Graph

\section{CONCLUSION}

This study provides organizations with valuable knowledge that would prompt them to make significant changes in the manner in which they currently proceed with the selection of any software project proposal which in turn could result in substantial savings in terms of economics (actual costs, time, and improved administrative procedures). The proposed system will: 1) enable active involvement of the users in the client organization in the software selection and development process; 2) enable the software vendor to have intimate relationship with the entire management of the client organization and hence has less challenges during users' requirements gathering; 3 ) enable users to easily accept, adopt and understand the use of the software when deplored.
AHP through its structured hierarchy of decision levels and pair wise comparison of elements for value judgment is more effective than utility models and scoring charts in working with semi-quantitative data as realistic inputs to the priority-setting agenda. They help to overcome in a significant way the fuzzy nature of quantitative information related to deliverable, logistics, and outcome. In the resource constrained situation of the developing countries, AHP provides a vital tool to select and rank projects based on judgmental evaluation through peer ratings. AHP provides a comprehensive and rational framework for structuring a decision problem, for representing and quantifying its elements, for relating those elements to overall goals, and for evaluating alternative solutions. It also considers 
a set of evaluation criteria, and a set of alternative scenarios among which the best decision is to be made. It generates a weight for each evaluation criterion and scenario according to the information provided by the Decision Maker (DM). AHP is effective in dealing with complex decision making because it reduces complex decisions to a series of pairwise comparisons. AHP reduces the bias in the decision making process because it also checks the consistency of the DM's evaluations.

\section{ACKNOWLEDGEMENTS}

Miss Damilola Egbekunle and Mr Taiwo Amoo are appreciated for the assistance provided during data collection for this research.

\section{COMPETING INTERESTS}

The authors declare that there are no competing interests regarding the publication of this paper.

\section{AUTHORS' CONTRIBUTIONS}

Dr Boluwaji Akinnuwesi designed the study, developed the research methodology, managed the literature searches and performed the literature review and wrote the first draft of the manuscript. Professor Faith-Michael Uzoka co-designed the study, supervised data collection, conducted the data analyses and did the final editing.

\section{REFERENCES}

1. Bredillet, C.N., Blowing hot and cold on project management. Project Management Journal, 2010. 41(3): p. 4-20.

2. Akinnuwesi, B.A., et al., An empirical analysis of end-user participation in software development projects in a developing country context. The Electronic Journal of Information Systems in Developing Countries, 2013. 58(6): p. 1-25.

3. Ika, L.A., Project success as a topic in project management journals. Project Management Journal, 2009. 40(4): p. 6-19.

4. Patanakul, P., B. lewwongcharoen, and D. Milosevic, An empirical study on the use of project management tools and techniques across project life-cycle and their impact on project success. Journal of General Management, 2010. 35(3): p. 41-65.

5. Rivard, S. and R. Dupré, Information systems project management in PMJ: $A$ brief history. Project Management Journal, 2009. 40(4): p. 2030.

6. He, J., B.S. Butler, and W.R. King, Team cognition: Development and evolution in software project teams. Journal of Management Information Systems, 2007. 24(2): p. 261-292.

7. Meso, P. and R. Jain, Agile software development: adaptive systems principles and best practices. Information Systems Management, 2006. 23(3): p. 19-30.

8. Wei, C. and M.J. Wang, $A$ comprehensive framework for selecting an ERP system.
International journal of project management, 2004. 22(2): p. 161-169.

9. Melone, N. and T. Wharton, Strategies for MIS project selection. Journal of Systems Management, 1984. 35(2): p. 26-33.

10. Rouyendegh, B.D. and T.E. Erkan, ERP system selection by AHP method: case study from Turkey. International Journal of Business and Management Studies, 2011. 3(1): p. 39-48.

11. Uzoka, F.M., et al., Identifying Factors for Evaluating Software Project Proposals. International Journal of Quality Engineering and Technology, 2016. 6(1/2): p. 93-114.

12. Verner, J., et al., What factors lead to software project failure and whose fault was it? Ingénierie des systèmes d'information, 2009. 14(4): p. 55-75.

13. Hwang, C.-L. and K. Yoon, Multiple attribute decision making: methods and applications a state-of-the-art survey. Vol. 186. 2012: Springer Science \& Business Media.

14. Yoon, K.P. and C.-L. Hwang, Multiple attribute decision making: an introduction. Vol. 104. 1995: Sage publications.

15. Hares, J. and D. Royle, Measuring the value of IT. Chichester ua, 1994.

16. Buss, M.D.J., How to rank computer projects. Harvard Business Review, 1983. 61(1): p. 118125.

17. Muralidhar, K., R. Santhanam, and R.L. Wilson, Using the analytic hierarchy process for information system project selection. Information \& Management, 1990. 18(2): p. 87-95.

18. Saaty, T.L., How to make a decision: the analytic hierarchy process. European journal of operational research, 1990. 48(1): p. 9-26.

19. Saaty, T.L., Decision making with the analytic hierarchy process. International journal of services sciences, 2008. 1(1): p. 83-98.

20. Verville, J. and A. Halingten, An investigation of the decision process for selecting an ERP software: the case of ESC. Management Decision, 2002. 40(3): p. 206-216.

21. Williams, J.B., et al., The structured clinical interview for DSM-III-R (SCID): II. Multisite testretest reliability. Archives of general psychiatry, 1992. 49(8): p. 630-636.

22. Sherer, S.A. IS project selection: the role of strategic vision and IT governance. in System Sciences, 2004. Proceedings of the 37th Annual Hawaii International Conference on. 2004. IEEE.

23. Molla, A. and P.S. Licker, eCommerce adoption in developing countries: a model and instrument. Information \& management, 2005. 42(6): p. 877899.

24. Uzoka, F.M., R.O. Abiola, and R. Nyangeresi, Influence of product and organizational constructs on ERP acquisition using an extended technology acceptance model. International Journal of enterprise information systems, 2008. 4(2): p. 67.

25. Niessink, F. and H. Van Vliet. Measurements should generate value, rather than data [software metrics]. in Software Metrics Symposium, 1999. Proceedings. Sixth International. 1999. IEEE. 
26. Kahraman, C., G. Büyüközkan, and D. Ruan, Measuring software development value using fuzzy logic, in Intelligent Sensory Evaluation. 2004, Springer. p. 285-308.

27. Akinnuwesi, B.A., et al., $A$ framework for usercentric model for evaluating the performance of distributed software system architecture. Expert Systems with Applications, 2012. 39(10): p. 93239339.

28. Akinnuwesi, B.A., F.M. Uzoka, and A.O. Osamiluyi, Neuro-Fuzzy Expert System for evaluating the performance of Distributed Software System Architecture. Expert Systems with Applications, 2013. 40(9): p. 3313-3327.

29. Seong Leem, C. and Y. Yoon, A maturity model and an evaluation system of software customer satisfaction: the case of software companies in Korea. Industrial Management \& Data Systems, 2004. 104(4): p. 347-354.

30. Akinnuwesi, B.A., et al., An empirical analysis of end-user participation in software development projects in a developing country context. The Electronic Journal of Information Systems in Developing Countries, 2013. 58(6): p. 1-25.

31. Verville, J. and A. Halingten, $A$ six stage model of the buying process for ERP software. Industrial Marketing Management, 2003. 32: p. 585-94.

32. Jadhav, A.S. and R.M. Sonar, Framework for evaluation and selection of the software packages: A hybrid knowledge based system approach. Journal of Systems and Software, 2011. 84(8): p. 1394-1407.

33. Wei, C.C., C.F. Chien, and M.J.J. Wang, An AHPbased approach to ERP system selection. International journal of production economics, 2005. 96(1): p. 47-62.

34. Oppermann, R. and H. Reiterer, Software Evaluation Using the 9241. Behaviour and Information Technology, 1997. 16(4/5): p. 232-245.

35. Haddara, M., ERP Selection: The SMART Way. Procedia Technology, 2014. 16: p. 394-403.

36. Lai, V.S., R.P. Trueblood, and B.K. Wong, Software selection: a case study of the application of the analytical hierarchical process to the selection of a multimedia authoring system. Information \& Management, 1999. 36(4): p. 221232.

37. Liu, O., et al., An intelligent decision support approach for reviewer assignment in $R \& D$ project selection. Computers in Industry, 2016. 76: p. 1-10.

38. Santhanam, R. and G.J. Kyparisis, A decision model for interdependent information system project selection. European Journal of Operational Research, 1996. 89(2): p. 380-399.

39. Santhanam, R. and J. Kyparisis, A multiple criteria decision model for information system project selection. Computers \& Operations Research, 1995. 22(8): p. 807-818.

40. Yet, B., et al., A Bayesian network framework for project cost, benefit and risk analysis with an agricultural development case study. Expert Systems with Applications, 2016. 60: p. 141-155.

41. Jadhav, A.S. and R.M. Sonar, Evaluating and selecting software packages: A review. Information and software technology, 2009. 51(3): p. 555-563.

42. Uzoka, F.M., et al., A multi-criteria framework for assessing scholarship based on Boyer's scholarship model. Information Knowledge Systems Management, 2013. 12(1): p. 25-51.

43. Uzoka, F.M.E., Examining the effects of TAM constructs on organizational software acquisition decision. Information Resources Management Journal (IRMJ), 2009. 22(3): p. 40-58.

44. Davis, L. and G. Williams, Evaluating and selecting simulation software using the analytic hierarchy process. Integrated manufacturing systems, 1994. 5(1): p. 23-32.

45. Khaddaj, S. and G. Horgan, The evaluation of software quality factors in very large information systems. Electronic Journal of Information Systems Evaluation, 2004. 7(1): p. 43-48.

46. Al-Harbi, K.M.A.-S., Application of the AHP in project management. International journal of project management, 2001. 19(1): p. 19-27.

47. Nandi, S., S. Paul, and M. Phadtare, An AHPbased construction project selection method. Decision, 2011. 38(1): p. 91-118.

48. Maidamisa, A.A., R. Ahmad, and M.I.A. Aziz, Selecting the appropriate decision alternatives using SM and AHP. International Journal of Computer Applications, 2012. 37(10): p. 14-18.

49. Vargas, R.V. and P. IPMA-B. Using the analytic hierarchy process (ahp) to select and prioritize projects in a portfolio. in PMI Global Congress 2010 North America. 2010. Available @ http://www.ricardo-vargas.com/wpcontent/uploads/downloads/articles/ricardo varga s ahp project selection en.pdf, Access Date: July 30, 2016.

50. Zielsdorff, C., et al., Enterprise resource planning (ERP) selection for a medical devices manufacturing company. International Journal of Business Information Systems, 2010. 6(2): p. 265293.

51. Chau, P.Y., Factors used in the selection of packaged software in small businesses: views of owners and managers. Information \& Management, 1995. 29(2): p. 71-78.

52. Liberatore, M.J. and B. Pollack-Johnson, Factors influencing the usage and selection of project management software. IEEE Transactions on Engineering Management, 2003. 50(2): p. 164174.

53. Saaty, T.L., Decision-making with the AHP: Why is the principal eigenvector necessary. European journal of operational research, 2003. 145(1): p. 85-91.

54. Saaty, T.L. and M. OZDEMIR, Priority as dominance in derived measurement: Invariance of the principal eigenvector. International Journal of Information Technology \& Decision Making, 2003. 2(02): p. 185-195. 